\title{
HABILIDADES PERCEPTIVAS E CULTURA: A CAPOEIRA COMO MODO DE VER E DE SER
}

\author{
Christine Zonzon ${ }^{1}$
}

\begin{abstract}
Resumo: A partir de um estudo do ensino e da prática da capoeira, focalizamos as qualidades que se constituem como critérios de excelência expressas pelos termos malícia, malandragem ou mandinga. Ressalta-se que a malícia caracteriza tanto os fazeres do corpo como as interações sociais do capoeirista, revelando-se como um modo de ser diante das tensões e conflitos potenciais. Essa perspectiva aponta para a dimensão existencial da experiência corporal e nos convida a uma releitura dessa tradição que tem se reforçado como emblema da cultura afrobrasileira, com significados étnico-políticos postos em destaque ao longo das últimas décadas. No texto que segue, propõe-se apreender as formas peculiares de atuar/ser do capoeirista associando-as ao desenvolvimento de habilidades perceptivas específicas, entre as quais os modos de atenção visual ocupam um lugar central. A investigação da visão e da motricidade que subjazem à atuação maliciosa do capoeirista procura enriquecer a discussão sobre as especifidades sensoriais próprias a cada cultura e demonstrar que o sentido da visão nem sempre se apresenta a serviço da cultura ocidental visualista, como o pretendem recentes estudos da antropologia dos sentidos. A abordagem visa a revisitar antigas questões em torno da cultura e da sua transmissão, inspirando-se nos aportes da fenomenologia e da antropologia cultural, notadamente através de uma interpretação dos conceitos de "habitar o mundo" de Maurice Merleau-Ponty e do "par organismo/ambiente" de Tim Ingold.
\end{abstract}

Palavras-Chave: Capoeira; Malícia; Malandragem; Mandinga.

Résumé : A partir d'une étude sur l' enseignement et la pratique de la capoeira, on s'intéresse aux qualités appelées malícia, malandragem ou mandinga qui apparaissent comme constitutives des critères d'excellence de cet univers. On remarque que la malícia caractérise tout autant les modes d'agir corporels que les interactions sociales du capoeiriste, étant plutôt un mode d'être face aux tensions et conflits potentiels. On voit ici révélée la dimension existentielle de l'expérience corporelle ce qui nous invite à une relecture de cette tradition qui a dernièrement assumé son role d'emblème de la culture afro-brésilienne en tant que pratique porteuse de significations ethniques et politiques. II s'agit donc ici d'apréhender les modes particuliers qui affectent les dimensions de l'être et les savoir-faire du capoeiriste en les associant au développement d'habilités perceptives spécifiques, au centre

1 Doutoranda em Ciências Sociais pelo Programa de Pós-Graduação em Ciências Socias da Universidade Federal da Bahia (UFBA); Capoeirista. Endereço eletrônico: criszom2@gma il.com. 
desquelles se trouvent les modes d'attention visuelle. L'étude de la vision et de la motricité sous-jacentes aux modes d'agir malicieux du capoeiriste s'insère dans l'actuel débat sur la dimension culturelle des perceptions sensorielles. L'objectif est de démontrer que la vision n'est pas toujours au service de la culture occidentale visualiste commme l'ont affirmé de recentes études issues de l'anthropologie des sens. La réflexion propose ainsi de revenir sur d'anciennes questions concernant la culture et sa transmission en s'inspirant des apports de la phénoménologie et de l'anthropologie culturelle, en se nourissant notamment de concepts tels que "habiter le monde » de Merleau-Ponty et de « dynamique corps/milieu) de Ingold.

Mots Clé : Capoeira; Malícia; Malandragem; Mandinga.

\section{INTRODUÇÃO - CAPOEIRA: UMA ARTE DA MALÍCIA}

No texto que segue, me proponho a desenvolver uma reflexão acerca dos vínculos entre habilidades corporais e sensoriais e aquilo que costumamos chamar de "cultura", a partir de um estudo da experiência corporal envolvida na prática da capoeira, qual seja uma tradição que tem se reforçado ao longo das últimas décadas como emblema da cultura afrobrasileira. Nesse intuito, examinarei um elemento central dessa prática lúdico-ritual, comumente chamado de malícia. Trata-se de um tipo de esperteza ou sabedoria que perpassa os modos de agir e interagir no jogo afetando a movimentação corporal, os golpes de ataque e defesa e o conjunto das ferramentas expressivas dos jogadores, como gestos e mímicas. Segundo afirmam os capoeiristas, a malícia pode e deve ser incorporada pela pessoa que se inicia na capoeira, tornando-se então parte da sua personalidade e passando a orientar seus comportamentos nas situações da vida cotidiana, notadamente no intuito de resolver conflito e adversidades da maneira a mais vantajosa. Em outras palavras, uma excelência adquirida no domínio do desempenho corporal acaba afetando a pessoa por inteiro e gera uma forma de ser, por vezes expressa através de metáforas como a expressão: ter jogo de cintura .

Um dos aspectos da malícia que merece atenção diz respeito à articulação entre o corpo individual e a cultura. Com efeito, não se trata apenas de uma competência entre outras, cujo domínio seria desenvolvido aleatoriamente por algumas pessoas, mas sim, da competência suprema que qualifica o capoeirista e faz com que seja reconhecido como tal. Assim, a malícia é o traço que melhor define a capoeira e uma das principais características que a diferencia de outras lutas ou artes marciais. Além do mais, embora a prática da capoeira se decline em estilos e modalidades 
diversas (notadamente a capoeira angola e a capoeira regional) e tenha modificado seus movimentos, seus rituais e seus significados ao longo dos últimos dois séculos ${ }^{2}$, a malícia perpassa a pluralidade das versões que conhecemos. Configura-se como chave da eficiência e do prestígio e constitui o mote dos discursos filosóficos e identitários oriundos das lideranças responsáveis pela transmissão. As elaborações nativas acerca da malícia deixam clara a existência de vínculos entre os fazeres do corpo e a cultura, entre as dimensões individuais e coletivas do corpo postas em destaque por uma prática sustentada por (e sustentando) uma "tradição" que se reivindica, ora como herança da cultura africana bantu, ora como invenção dos negros escravizados do Recôncavo baiano ${ }^{3}$.

A reflexão sobre a malícia tal como brevemente delineada acima se inscreve numa proposta de entendimento da experiência que possa conjugar a vivência prática, corporal e os sentidos que lhe são inerentes. Nesse objetivo, tenta-se encontrar um caminho analítico que não separe a materialidade do corpo das suas dimensões sociais, culturais e políticas. Vale lembrar que essa questão envolve conceitos que a tradição filosófica, e no seu rastro as análises sociológicas e antropológicas, têm apreendido sob uma forma dicotômica: natureza/cultura; indivíduo/sociedade; corpo/mente; real/simbólico. Assim, observamos que, em sua maioria, as soluções propostas para articular essas polaridades consistem em apreender o sócio-histórico como causa do corporal ou então em interpretar o corporal como representação do social ${ }^{4}$.

2 O marco de dois séculos apenas refere ao período investigado pelos historiadores da capoeira, o que não invalida, é claro, que o jogo tenha existido, sob diversas formas, antes dessa data.

3

Há divergência entre as versões apresentadas na capoeira angola e na capoeira regional. Para os primeiros, a capoeira estaria associada à cosmovisão dos povos da África ocidental enquanto os segundos localizam a criação da capoeira no contexto da escravidão.

4 No âmbito dos estudos sobre a capoeira, três grandes linhas interpretativas podem ser destacadas:

a) a primeira propõe compreender o jogo da capoeira como herança da trajetória histórica da diáspora africana no Brasil. Nessa perspectiva, a malícia é tida como estratégia de sobrevivência e de resistência diante da violência e da desigualdade inerentes ao contexto colonial escravagista. Tratar-se-ia de uma modalidade de luta do mais fraco diante do mais forte. A análise apreende, portanto, os fazeres corporais como o legado de relações sociais e/ou a sua incorporação. O termo que melhor expressa essa significação sociohistórica é o de "malandragem" (ver, por exemplo, DIAS, 2006);

b) uma segunda proposta, por vezes associada à primeira, põe em destaque a vertente étnica e cultural da prática da capoeira. As análises repousam sobre o pressuposto de 
Voltemos a observar mais atentamente o que é a malícia recorrendo aos termos usados para expressar esse estilo de atuação. Os capoeiristas dispõem de um largo repertório com esse propósito, sendo as palavras as mais usuais: traição, brincadeira, esperteza, manha, maldade, malandragem, mandinga. Fica bastante claro que se trata de termos com conotações bem diferentes, ou até mesmo opostas, que vão da inocência da brincadeira até a imoralidade da maldade ou da traição, sem contar a evocação da magia com a mandinga e da inteligência com a esperteza. Isso porque lançar mão da malícia é declinar a multiplicidade dos potenciais expressivos do corpo produzindo ações variadas e imprevisíveis no intuito de surpreender e iludir o adversário. Em outras palavras, a malícia consistiria em um jogo com as aparências, como o disfarce das intenções e das ações (o "faz de conta"), o jogador tirando partido - ou como veremos, desenvolvendo (d)essa qualidade peculiar do corpo, de ser situado numa posição intermediária entre o interno e o externo, entre eu e o mundo, que levou James a afirmar: " O corpo em si é a principal instância do ambíguo" (JAMES apud LATOUR, 2007, p. 40).

É sobre a ambigüidade do corpo que irei me debruçar nesse estudo da malícia. O ponto de partida é o corpo malicioso e ambíguo, um corpo que desenvolve a capacidade de produzir e de desvendar a ilusão, através do processo de aprendizagem da capoeira. As temáticas abordadas giram então em torno da aquisição de habilidades corporais e perceptivas sobre as quais repousa o "faz de conta".

uma continuidade das expressões culturais entre a África e o Brasil, e reconhecem no jogo brasileiro uma ressignificação de rituais africanos (a fonte mais bem aceita dessa versão seria a capoeira derivar da dança do N'Golo). Nessa vertente analítica, a malícia se expressa mais adequadamente através da palavra "mandinga"que evoca o universo mágico-religioso, a competência do capoeirista encontrando-se assim associada à espiritualidade ou, de modo mais prático, à sua vinculação com entidades que o auxiliam na hora do jogo. A significação da capoeira está vinculada a alguma essência (seja étnica, seja cultural) do povo negro e remete à permanência de um sistema de valores e de uma cosmovisão no contexto de dominação da cultura ocidental (ABIB, 2005);

c) a terceira linha, menos explorada, inverte a leitura, dando como ponto de partida à análise a própria prática da capoeira na sua dimensão corporal. São trazidas à tona configurações, estruturas, regularidades dos movimentos - da musicalidade, do ritual etc. elementos esses que são interpretados como símbolos de configurações ou relações sociais. Mais especificamente no que diz respeito à malícia, elabora-se assim uma interpretação das características da gestualidade (duplicidade, jogos teatrais, inversão, etc.) como sendo representações de conteúdos políticos e sociais que ficariam ocultos nos contextos da vida cotidiana (ver: REIS, 2000; ZONZON, 2001; DOWNEY, 2005).

156 Número temático: Literatura, cultura e memória negra. A Cor das Letras - UEFS, n. 12, 2011 
Conjugam-se diversos elementos para que essa abordagem se concentre prioritariamente na habilidade visual. $O$ primeiro motivo é que a visão está mais obviamente vinculada ao domínio das aparências e da ilusão, e consequentemente, está diretamente envolvida no savoir-faire malicioso da malícia. Também constatamos, a partir da própria experiência de aprendizagem e das observações das formas de transmissão da capoeira, que a orientação mais geral e recorrente de mestres a alunos refere-se à necessidade de olhar os movimentos e atitudes do adversário. Por outro lado, a competência visual torna-se central na iniciação, pois, afirmam esses mestres, a malícia não pode ser explicada nem ensinada, antes seria o fruto da experiência do fazer e do ver fazer. A malícia, e a capoeira no seu conjunto, se aprendem observando os modelos apresentados pelos capoeiristas mais experientes.

Se esses argumentos justificam o predomínio conferido à visão na discussão que segue, é relevante situar essa abordagem em meio às discussões sobre as articulações entre sentidos e cultura e, mais particularmente, confrontar os argumentos que denunciam a hegemonia da habilidade visual.

\section{VISÃO E VISUALISMO}

A temática da visão ocupa um lugar de destaque na antropologia dos sentidos. Essa linha de estudo que emerge em volta dos anos 90 do século $\mathrm{XX}$ e põe em foco os mundos sensórios que subjazem às diferentes culturas denuncia a hegemonia da visão associada ao projeto da modernidade ocidental. A cultura do visual, ou "visualismo" teria se desenvolvido em detrimento dos outros sentidos (tato, audição, olfato) em sociedades que promoveram o culto da imagem. Assim, a denúncia - por vezes legítima - de uma ideologia e uma estética hiper-visual que fazem do mundo um espetáculo acaba recaindo nas propriedades intrínsecas do sentido da visão.

Nessa perspectiva, diferentes estudos se empenharam a demonstrar que as culturas "indígenas", ainda preservadas desse visualismo, concediam um papel central aos demais sentidos. Por exemplo, as etnografias de Stoller, Seeger e Gell - comentadas por Ingold (2000) - tendo respectivamente como objeto povos do Niger, do Brasil e da Nova Guiné, concluem que há uma primazia do sentido da audição nesses grupos. Feito esse constato, um segundo passo é dado atribuindo-se à audição qualidades que seriam supostamente ausentes da visão. Retomo aqui a síntese crítica de Ingold que 
esquematizou o contraste entre os dois sentidos apresentado por esses antropólogos:

[...] o som penetra enquanto a visão isola; o que ouvimos são sons que enchem o espaço à nossa volta enquanto o que vemos são objetos abstraídos ou "recortados" do espaço diante de nós; o corpo responde ao som como uma cavidade ressoante e à luz como uma tela refletora; o mundo auditivo é dinâmico e o mundo visual estático; ouvir é participar enquanto ver é observar à distância; a audição é moralmente virtuosa enquanto a visão é intrinsecamente inconfiável; a audição é solidária enquanto a visão é indiferente ou, até, traiçoeira.

Nos rastros da análise crítica de Ingold que desconstrói a argumentação da antropologia dos sentidos e demonstra que essa corrente continua aprisionada na dicotomia corpo/mente, quero voltar à proposta dessa seção, confrontando a experiência visual da malícia com essas (e outras) leituras sobre a natureza da visão. Uma vez que a tradição da capoeira define-se como um resgate dos valores e da cosmovisão da cultura africana e/ou como herança da resistência à dominação colonial européia, interrogar a visão que fundamenta essa prática pode alimentar o argumento de Ingold de que "é através da sua cooptação a serviço de um projeto peculiarmente moderno de objetificação que a visão tem sido reduzida à faculdade de reflexão pura e desinteressada" (2000) e revelar uma visão participativa e dinâmica, muito distante da idéia de um sentido que fornece imagens e representações.

Trata-se de considerar como as pessoas realmente vêem, ou seja, trazer para conhecimento e discussão um modo de visão formatado pelas circunstâncias peculiares da aprendizagem e do jogo da capoeira. Nessa perspectiva, a visão não é apreendida como um estímulo específico, diferente da audição ou do tato, por exemplo, mas do ponto de vista de um corpo engajado num ambiente e numa prática específica, como sugerem os esquemas de Merleau-Ponty, Latour e Despret, além do próprio Ingold. Para este fim, retomo dados etnográficos levantados numa pesquisa sobre a aprendizagem corporal da capoeira angola ${ }^{5}$, dando destaque ao desenvolvimento das percepções e levando em conta a centralidade do olhar no conjunto dos sentidos mobilizados, sem deixar de considerar esse conjunto e suas articulações com a atividade motora.

5 Dissertação de Mestrado: Capoeira angola: os sentidos em jogo (ZONZON, 2007).

158 Número temático: Literatura, cultura e memória negra. A Cor das Letras - UEFS, n. 12, 2011 


\section{APRENDER A VER}

Referindo à aprendizagem da capoeira, por volta dos anos trinta a quarenta do século passado, o historiador Frede Abreu afirma que a iniciação no jogo se dava na própria roda de capoeira, num procedimento chamado de "oitiva"6 (ABREU, 2003). Era observando os grandes capoeiristas que se aprendiam os principais movimentos assim como os rituais e códigos do jogo, numa época em que não existiam academias nem ensino sistematizado da capoeira. Com a estruturação de locais e formatos próprios à aprendizagem (principalmente a partir dos anos 50), os processos de transmissão diversificaram sem, no entanto, destituir a habilidade visual da sua importância, inclusivo porque a imitação do modelo dos "mais velhos" ainda permanece fundamental na aquisição das habilidades corporais dos "mais novos"".

Acompanhando o dia a dia dos treinos em uma academia de capoeira, nota-se que a centralidade do sentido da visão é evocada pelos mestres durante todo o processo de aprendizagem através de constantes e explícitas injunções. Olhe! Olhe para seu adversário! Você não está olhando! São orientações ouvidas milhares de vezes pelos novatos, proferidas na ocasião do jogo na roda ou de exercícios efetuados em dupla visando a aquisição de movimentos e golpes. Quando os movimentos são executados individualmente, um objeto - um caxixi ou uma cadeira, por exemplo - é colocado no centro do salão fazendo ofício de ponto de focalização para o olhar dos capoeiristas posicionados na sua volta, configuração essa que indica desde já a estreita vinculação entre a motricidade e o olhar.

A insistência na necessidade de olhar que perpassa a didática da capoeira tem como contrapartida a dificuldade de ver relatada pelos aprendi-

6 Notemos que o termo oitiva é usado nesse contexto para designar a observação, enquanto no seu sentido original refere-se à audição (como aliás o conhecemos na linguagem jurídica), o que deixa claro a estreita associação entre esses dois sentidos. Seria portanto mais exato associar a aprendizagem por oitiva à aprendizagem in loco, presencial ou participativa.

7 Não abordarei aqui a questão da imitação, por constituir-se como uma problemática extensa e controvertida. O antropólogo e capoeirista estadunidense Greg Downey consagrou um artigo à discussão da imitação na aprendizagem na capoeira ressaltando os limites desse modo de enculturação (DOWNEY, 2010). Do lado dos pontos de vista nativos, não podemos deixar de lembrar um ditado repetitivamente citado por Mestre Valmir, líder de um grupo de capoeira angola de Salvador, em momentos do treino em que os alunos ficam observando os exercícios sem executá-los: se se aprendesse olhando, cachorro seria açougueiro!. Ou seja, a visão sem o movimento não produz aprendizagem. 
zes. A sensação de "não estar vendo nada" impõe-se de modo quase generalizado nas primeiras experiências de jogo na roda ${ }^{8}$. Esses dois pólos da problematização da visão (as instruções para olhar e as dificuldades para ver) apontam para o fato que a visão do capoeirista é o resultado de um longo processo de reformatação e de expansão. No final da escala de competências perceptivas que corresponde à posição ocupada pelos mestres, encontramos um tipo de visão quase onisciente como atestam essas observações de campo numa roda de capoeira angola:

V. (o mestre) está no berimbau, tocando e cantando. Entre dois versos, chama um aluno e troca com ele algumas palavras. Era para pedir que atenda uma visitante que entrou na porta errada do outro lado do salão, nas suas costas! [Nota de campo, FICA, 25.03.2006] (ZONZON, 2007, p. 78).

A visão alcançando os 360 graus em torno do corpo constitui uma meta ou ideal de eficiência visual, aliás, metaforizada pelo ditado: Capoeirista é como abacaxi, não tem costa.

\section{VISÃO E ESPACIALIDADE}

A reeducação da visão está associada à ressignificação do corpo e do espaço, pondo em jogo as articulações entre intenção, visão e movimento. Todo movimento realizado dirige-se a um ponto enfocado visualmente no espaço, que pode constituir-se apenas como uma direção, como no caso do objeto/foco utilizado nos treinos e aludido acima ou ser um alvo que o meu corpo alcança com uma precisão extrema, pois, se a distância for muita o golpe perde seu sentido, mas se for pouca, arrisca ferir perigosamente - o corpo ou a honra - (d)o adversário ${ }^{9}$. No jogo propriamente dito, toda mo-

8 Essa perda da visão está associada à incapacidade de ouvir. O vínculo entre esses dois sentidos será abordado a seguir.

9 O primeiro caso, de um golpe mal direcionado ou distante do foco, é tematizado por um verso de cantiga com função didática que pode ser cantada pelo coro para comentar o jogo em curso na roda: Na roda de capoeira, nunca dê seu golpe em vão. O segundo extremo, o movimento atingindo o corpo do adversário, é igualmente tido como descontrole corporal ou emocional, isto é como falta de sabedoria. A tradição ilustra essa justa medida dando o exemplo dos capoeiristas de outrora que "brincavam" na roda vestindo ternos brancos e saiam com a roupa impecável, demonstrando assim que nenhum golpe tinha atingido seu corpo. Essa capacidade de medir exatamente a direção e a distância do movimento constitui-se como ideal de excelência, o que não impede que sejam aplicados, na prática, golpes impactantes deliberadamente, por vezes com bastante força, pois tudo que se proclama como "fundamento" (tradição legítima concernente às formas de agir e de ser) se flexibiliza em função das circunstâncias e, principalmente, ao favor das 160 Número temático: Literatura, cultura e memória negra. A Cor das Letras - UEFS, n. 12, 2011 
vimentação se dá, portanto, em direção a ou, complementarmente, afastando-se de outro corpo igualmente em movimento o que implica numa simultaneidade do ver e do mover-se.

A imbricação das atividades perceptivas e motoras suscita uma extensa análise de Merleau-Ponty em Fenomenologia da Percepção, obra em que o autor se dedica a demonstrar a complementaridade dessas habilidades. Observa que o sentido da visão e o sentido do tato, envolvidos no ato de apreensão de um objeto, não se encontram em justaposição, mas conformam uma experiência integral, o visual dando sua qualidade ao tato e vice versa. Assim, argumenta ele, não preciso me representar o espaço objetivo nem acompanhar visualmente meu gesto desde seu início para tocar um objeto na minha frente; olhando para esse alvo, a minha mão se dirige com segurança até o ponto exato em que se encontra (MERLEAUPONTY, 1945, p. 150) Nesse sentido, em vez de definidos como posições objetivas em relação à posição objetiva de nosso corpo, os lugares no espaço inscrevem em nossa volta o alcance de nossos gestos, e conhecemos o espaço (e "temos" um espaço) pelos nossos hábitos corporais.

Notemos que tal conhecimento inato do próprio corpo e do mundo, ou mais exatamente da espacialidade do corpo no seu ambiente, que permite ao corpo deslocar-se sem recorrer a racionalizações nem a representações, é o que cai por terra na nova experiência corporal suscitada pela prática da capoeira. A razão principal dessa desorientação espacial me parece estar vinculada ao predomínio de duas figuras recorrentes na movimentação: a rotação do corpo e a permutação alto/baixo.

Sem entrar numa descrição pormenorizada dos movimentos da capoeira, é preciso considerar que o jogo, que envolve um diálogo corporal em dupla, inclui um grande número de posições e golpes em que o corpo se encontra de cabeça para baixo, as mãos assumindo a função de sustentação e de deslocamento que cabe normalmente aos pés, eventualmente auxiliadas pelo apóio da cabeça no chão ${ }^{10}$. Também é relevante precisar que a quase totalidade dos golpes e das defesas desenham movimentos circulares e/ou indiretos (a trajetória do movimento raramente é uma linha reta), e em muitos casos, a permutação está associada à rotação.

relações de poder que tornam as ações dos dominantes (mestres, capoeiristas mais ve10 Ihos ou de prestígio) legítimas.

É o caso dos movimentos mais fundamentais do jogo na capoeira angola, nominalmente: o rabo de arraia, o aú, o rolê, a queda de rim assim como de outros mais complexos como a bananeira, o pião, o charuto. 
O domínio desse repertório implica numa ressignificação corporal completa em que se destaca a aquisição de força muscular nos membros superiores e na região cervical assim como o desenvolvimento do equilíbrio do corpo em posições invertidas e nas rotações. Associada a essas alterações que dizem respeito a componentes fisiológicos do corpo (músculos, pele, articulações, etc.) tem lugar uma profunda ressignificação das percepções sensoriais.

As experiências dos novatos na capoeira e a observação do processo de aprendizagem dos movimentos mostram que a inversão do corpo acarreta uma sensação de total desorientação corporal afetando tanto a percepção do entorno quanto do próprio corpo. Nas posições de permutação do alto/baixo corporal, os aprendizes capoeiristas deixam de ver o que está em sua volta ao passo que parecem perder a consciência do próprio corpo. Não sabem se suas pernas estão dobradas ou esticadas e também sentem dificuldade em identificar e controlar o lado para o qual estão direcionando seus movimentos. Essas dificuldades adquirem maior acuidade quando à permutação se associa um movimento de rotação.

Um ponto relevante para se pensar a visão como um sentido imbricado nas demais dimensões da percepção, enquanto participando de um mesmo corpo, é que a perda da visão nas condições de inversão (e rotação) do espaço não se dá sob a forma de uma cegueira em relação às coisas externas. Não é uma simples falta de visão de objetos. Pareceria antes que a pessoa não sabe mais o que significa ver, assim como não sabe onde está seu corpo. Talvez então não possa ver porque não tem corpo. Aliás, voltar a ver, ou melhor, começar a ver jogando capoeira, é um processo aliado à eficiência do movimento, como se o corpo no seu conjunto pudesse enfim entrar no jogo.

Essas constatações revelam traços da visão incompatíveis com aqueles que supostamente caracterizariam a observação passiva e a distinguiria dos outros sentidos. Em estreita associação com o movimento, a visão maliciosa do capoeirista pode portanto ser melhor compreendida enquanto interação ou fluxo.

\section{A FUGACIDADE DA VISÃO E DO MUNDO}

A palavra "posição" utilizada acima para descrever o repertório corporal da capoeira, não dá conta de traduzir a movimentação incessante que anima o corpo dos jogadores. Até mesmo quando se evoca a posição invertida, seria preciso acrescentar que apenas se constitui como uma das inú162 Número temático: Literatura, cultura e memória negra. A Cor das Letras - UEFS, n. 12, 2011 
meras posturas do corpo, dando-se em alternância com outras, encadeadas num fluxo contínuo de movimentos que os capoeiristas costumam chamar de "diálogo corporal".

Desta forma, se considerarmos que os jogadores orientam o seu oIhar na direção do adversário em movimento - somando-se as variáveis do movimento próprio com as variáveis do movimento do outro - pode-se dizer que esse olhar está engajado no fluxo dinâmico do jogo, isto é num fluxo temporal. Nesse sentido, a visão do capoeirista se assemelha à audição: seus objetos têm uma natureza efêmera; assim como o som, eles não existem para além do tempo da sua percepção. Por se tratar de movimentos, apresentam certa semelhança com a dita língua dos sinais usada pelos surdos. Como nota Ingold (2000), "Não há como pará-los para uma inspeção. Como sons da fala, gestos sinalizados existem apenas de passagem. $O$ fato de que são vistos e não ouvidos não os faz menos fugazes".

Ora, a idéia defendida pela antropologia dos sentidos e que constitui um dos pontos daquilo que Ingold chama de "grande divisor" entre a visão e os demais sentidos, e por derivação, entre as sociedades ocidentais e as outras, é de que o mundo acessado através da visão é estático, que os objetos visuais encontram-se já lá, independentemente da atividade perceptiva. Nela repousa o conceito de exterioridade do objeto visual que teria como contrapartida a penetração do som no sujeito que ouve.

A formatação do olhar do capoeirista para um mundo visual intermitente $^{11}$ parece indicar uma equivalência entre os sentidos da visão e da audição e põe em dúvida qualquer categorização dos sentidos baseada em qualidades que lhe seriam inerentes. As dificuldades encontradas no percurso de aprendizagem, já evocadas acima, evidenciam a solidariedade das percepções e da motricidade. Com efeito, é relevante notar que, na ocasião das primeiras experiências na roda, além de sentir-se incapaz de ver o adversário e tudo que está em volta, o iniciante não ouve nem o ritmo da bateria musical, nem as mensagens expressas nas cantigas, nem a chamada do berimbau anunciando o final do jogo ${ }^{12}$.

11 Retomo aqui ao proveito da minha argumentação a formulação "natureza intermitente do mundo" utilizada por um cego para descrever o mundo acústico, E acrescenta: "O mundo visto nunca pode escapar aos olhos, ele está sempre lá, e pode-se retornar a ele repetidas vezes. Mas o mundo do som foge tão rápido quanto chega à existência" (HULL apud INGOLD, 2000).

12 Refiro aqui a alguns elementos do ritual da roda. A bateria musical é o conjunto dos instrumentos (comportando geralmente berimbaus, pandeiros, atabaque, caxixi e recoreco) que orienta a cadência do jogo. Por mensagens nas cantigas, entende-se a inclusão 
Ver, ouvir e mover-se se encontram imbricados no jogo da capoeira de modo indissociável, ainda mais porque o que os corpos são movidos pelo ritmo e as melodias da bateria musical. É preciso lembrar que, para os capoeiristas, o berimbau é tido como sendo o mestre do ritual da roda, aquele que ensina, comanda e inspira as interações corporais, transmitindo a energia, o axé.

A experiência do capoeirista alimenta portanto a argumentação crítica de Ingold e ecoa com as considerações de Merleau-Ponty sobre o fenômeno de sinergia sensorial. Segundo o filósofo francês, "o meu corpo não é uma soma de órgãos justapostos, mas um sistema sinérgico cujas funções são retomadas e vinculadas no movimento geral do ser ao mundo" (MERLEAU-PONTY, 1945, p. 280 - trad. minha). Retomando a idéia de um movimento geral do ser ao mundo, a capoeira apresentar-se-ia assim como um modo de agir e de ser envolvendo uma constante atenção para com o entorno, um estado de prontidão visual, auditiva e sinestésica posta ao serviço do jogo.

\section{VER E SER VISTO}

Vimos (não há como evitar a metáfora!) que a visão que orienta a movimentação do capoeirista emerge de - e gera - uma reorientação espacial e acompanha um fluxo semelhante ao da audição. Essas qualidades foram atribuídas à natureza móvel do objeto, ou seja, que a análise isolou um sujeito que vê de um objeto visto. Mas na interação que configura o jogo, cada pessoa é ao mesmo tempo sujeito e objeto da visão: é preciso ver o movimento do outro ao tempo que vai ser visto por esse outro. Movimentos e visão aparecem como indissociáveis nessa dinâmica, o meu olhar orienta o meu movimento que por sua vez desencadeia um movimento de resposta do outro, como se dá numa conversa - o que justifica o uso pelos capoeiristas dos termos "diálogo corporal" e "pergunta e resposta" designando respectivamente o jogo e a alternância dos movimentos de cada jogador semelhante àquela dos turnos de conversa. E levando em conta o fato que o objetivo é de superar o desempenho do adversário, mos-

de versos improvisados expressando comentários sobre a atuação dos capoeiristas e por vezes, dando conselhos ou instruções. A chamada do berimbau consiste em um toque específico anunciando a interrupção ou o final do jogo. Ignorar esse apelo é tido como sinal de imperícia grave.

164 Número temático: Literatura, cultura e memória negra. A Cor das Letras - UEFS, n. 12, 2011 
trando-se mais ágil e imprevisível do que este, cria-se uma disputa em torno da visibilidade, pois preciso ver mais do que sou visto.

Sendo assim, o jogador usa de técnicas corporais e de jogos teatrais no intuito de produzir aparências. Estes consistem em disfarçar intenções, mudando repentinamente a direção ou a intensidade do golpe, balançando o corpo para ambos os lados para soltar o movimento no momento mais inesperado, escondendo o ataque nascendo da cintura com amplos movimentos dos braços, por exemplo, ou ainda fingindo que está desatento ou machucado para atrair uma aproximação mais desprevenida do adversário. O jogo de "faz de conta" não só revela mais um desafio ao olhar (somado à inversão e ao movimento) como traz para discussão a outra face da visão, o visto, não sob a forma de um objeto, mas sim de um fazer. Nesse sentido, não é o "ser visto" que configura o invés do ver na capoeira, mas sim, o "parecer".

Esse último ponto merece maior reflexão uma vez que a natureza ilusória da visão é justamente uma das características destacadas pelos antropólogos na argumentação anti-visualista que sintetizamos no início dessa exposição (lembrando: "a audição é solidária enquanto a visão é indiferente ou, até, traiçoeira", o que, de fato, remete ao nome de "traição" designando a malícia e a capoeira nos tempos de outrora ${ }^{13}$ ). Ora, o exercício da capoeira parece não só reconhecer essa natureza ilusória do visto como promover e acentuar esse potencial de engodo. Notemos, no entanto, que o desenvolvimento dos efeitos de ilusão tem como contrapartida o desenvolvimento recíproco da capacidade de desvendar a ilusão. As habilidades complementares poderiam ser formuladas em termos de oferecer uma falsa aparência ao olhar do outro, por um lado, e desconfiar das aparências, ver sob a aparência, do outro.

Contudo, cabe perguntar se haveria um "objeto real" por baixo da aparência? Essa hipótese levaria a pressupor a existência de algo verdadeiro - um movimento, uma intenção, a expressão de um sentimento - que permaneceria constante no fluxo temporal da interação. Mas aquilo que era fingido pode se tornar verdadeiro e vice versa. A própria dinâmica do jogo desencadeia novas intenções, movimentos e expressões a cada instante, pois os fazeres dos jogadores se reajustam em função dos seus "lances" respectivos. Em suma, parafraseando uma imagem clássica da antropologia cultural (GEERTZ, 1989) em que se explora os significados de um piscar de

13 O termo "traição" é repetitivamente usado por Mestre Noronha em seus Manuscritos, por exemplo, para designar ora a capoeira, ora a malícia (v. COUTINHO, 1993). 
olho, e transferindo-a para o contexto do jogo malicioso da capoeira - cujo repertório gestual também compreende mímicas - , uma piscadela pode até ser o efeito de uma gota de suor que caiu no olho, um discreto sinal de cumplicidade dirigido a um parceiro, um falso sinal de cumplicidade destinado a ser visto por todos, ou todas essas coisas numa sucessão tão rápida que tende à simultaneidade, a sensação de ardor dando início a um jogo de disfarces que, por sua vez, suscita novas reações e sensações.

Pode-se concluir então que a visão deixa de ser uma apreensão de objetos ou de qualquer realidade supostamente escondida por baixo das aparências para assumir-se como um jogo entre o ver e o visto. A visão encontra-se engajada no conjunto do jogo, e é o jogo que constituiria o projeto em que o corpo se envolve. Assim como os corpos medem suas habilidades de destreza, equilíbrio e criatividade, os olhares competem em torno da percepção mais aguçada e extensa. E a relação entre visão e movimentos não consiste simplesmente em um paralelismo. Em vez de uma analogia, deve-se pensar num transbordamento de uma atividade na outra (perceptiva e motora), e conceber que é essa mesma relação (o transbordar) que interliga as duas pessoas em interação: o olhar de um prolonga-se no olhar do outro e cada movimento é completado por um movimento do seu par, mas também de forma cruzada, a visão de um para o movimento do outro e vice versa.

Sem se confundir um com outro - é uma luta - , os dois corpos coincidem para criar uma forma: o jogo. Não há ganhador nem perdedor, é o jogo que tem que ser bonito, imbricando-se os corpos ao ponto que, por vezes, deixam de se distinguir, e o que se vê são movimentos e curvas, espelhando-se e desenhando trajetórias no espaço. Beirando a dissolução da identidade? Canta-se: era eu, era meu mano; era meu mano, era eu.

\section{CONCLUSÃO - CORPO E MODO DE SER}

A capoeira é um jogo que precisa ser levado a sério, pois, como dizem os mestres, "não basta jogar as pernas para cima". Adentra-se em um universo onde as fronteiras entre o que é fingido e aquilo que é "real", entre a brincadeira e o risco, entre o meu corpo e o corpo do outro estão incertas, móveis, ambíguas. É o reino da malícia, da habilidade para discernir, mudar repentinamente de direção, de intenção ou de sentimento. Ver sem ser visto, produzir e desvendar a ilusão. Ou ainda, ser despistado e seguir à espreita de uma nova oportunidade. Jogar significa engajar-se no fluxo do espaço e do tempo em constante movimento, imbricar o seu corpo "físico", 166 Número temático: Literatura, cultura e memória negra. A Cor das Letras - UEFS, n. 12, 2011 
seus sentidos (notadamente a visão e a audição, como vimos) no fluxo do mundo.

Enquanto prática iniciática, os ensinamentos visam a dotar os praticantes de uma sabedoria que não se esgota na interação ritual da roda de capoeira: É preciso saber jogar na "pequena roda de capoeira" e na "grande roda da vida". Lança-se mão dessas habilidades no mundo cotidiano, pois, como o sugerem os dizeres dos capoeiristas, "a vida lá fora" oferece desafios, senão semelhantes aos da roda, pelo menos de um mesmo tipo: conflitos potenciais, acidentes, intrigas, oportunidades fugazes. Em ambos ambientes, as habilidades perceptivas permitem detectar as mudanças do seu entorno e tornam o capoeirista capaz de criar respostas adaptadas às circunstâncias de cada nova configuração. Os modos de atenção (CSORDAS, $2008)^{14}$ desenvolvidos na aprendizagem do jogo aliados ao estado de alerta, ou desconfiança quanto à atuação do parceiro, são progressivamente incorporados pelos praticantes, tornando-se atuantes no seu dia a dia. Ser malicioso na roda da vida envolve, de fato, uma habilidade para captar e reagir rapidamente, pressentir, prever, anteceder algum acontecimento... Mas também adiar, saber que o tempo de responder, resolver, reagir ainda não chegou, saber a hora certa. Trata-se de perceber o mundo sob a ação do tempo, nesse mesmo fluxo em que o olhar persegue os movimentos; e agir implica saber se situar ao cruzamento do tempo com o movimento sob a forma da oportunidade.

A leitura do esquema de Merleau-Ponty inspira um entendimento da analogia entre pequena roda da capoeira e grande roda da vida, pensando na habilidade desempenhada no jogo como "estilo", isto é uma relação préreflexiva na qual o corpo se sintoniza com uma situação através das percepções sensoriais e do movimento. Em outras palavras, corpo e meio são constitutivos um do outro, como já foi ressaltado a partir da experiência da espacialidade quando o aprendiz perde - e reencontra - a percepção/consciência de sue próprio corpo e do seu entorno. A noção de estilo - palavra que também remete à designação do tipo de movimento e dos jogos de corpo no universo da capoeira ${ }^{15}$ - abre caminho para apreender a

14 Com a formulação original "modos somáticos de atenção", Thomas Csordas (2008, p. 138) define "as formas culturalmente elaboradas de atentar com e para o corpo em contextos que envolvem a presença encarnada de outros".

Os estilos de capoeira regional e angola, além de corresponder a posicionamentos diferentes em termos de identidade étnica e política, estariam associados a modos de ser no mundo distintos. Uma vez que cada um envolve uma movimentação, uma relação com o 
experiência corporal como totalidade, ao mesmo tempo coisa e idéia, sendo então o sentido inseparável da materialidade dos fazeres. Escapa-se assim das abordagens que apreendem as práticas rituais como símbolo ou representação de uma instância social ou existencial, como é o caso quando interpretamos o jogo da capoeira como representação simbólica das relações históricas de desigualdade ou violência.

Como o argumenta Rabello (2003), a fenomenologia de MerleauPonty desloca os questionamentos das Ciências Sociais no tocante à relação entre o corpo e os significados sociais e políticos:

[...] nem a sociologia nem a antropologia avançam muito no entendimento da vida social ao mostrar que significados sociais, políticos, econômicos (relações de poder e desigualdades) são expressos através de imagens corporais (ou de arranjos espaciais), como se seu conteúdo original, ao ser transferido para o campo das características e funções do corpo físico, apenas ganhasse aí uma tonalidade mais viva ou mesmo um maior poder de persuasão. [...] Se levarmos a sério a noção de sentidos carnais, proposta por Merleau-Ponty, devemos, então, pensar na dinâmica de poder que vigora em um certo campo social [...] como sentido aderido aos corpos e coisas, formando com eles um contexto total de experiência.

A experiência do corpo, tal como descrita pelos capoeiristas ecoa com essa formulação, pois, segundo afirmam, reúne as dimensões físicas e espirituais, individuais e coletivas, lúdicas e sócio-políticas no seu mesmo jogo de malícia. Procurei demonstrar nesse texto que o processo de expansão e de refinamento das percepções sensoriais já delineia um estilo próprio afetando os modos de ser e de fazer e que a prática engaja o capoeirista em um "contexto total de experiência". Tal estilo apresenta semelhanças com categorias típicas construídas pelas Ciências Sociais, como o malandro de Roberto da Matta ${ }^{16}$, e/ou partilha traços de outras expressões culturais de origem africana, mas não tem como existir, ser realizado e perpetuado fora da experiência do corpo. Se a história foi determinante na construção da capoeira, esse legado está presente e ativo, agora, no modo em que o jogador percebe e dialoga com seu(s) mundo(s), da roda e da vida. Não

tempo e com o espaço próprias, a diversidade do sentido inerente à prática é experimentada na experiência corporal em si.

É interessante notar que, segundo o antropólogo Roberto DaMatta, o que caracteriza a malandragem é o uso da ambigüidade como instrumento de vida o que remete diretamente à posição de ambigüidade do corpo desenvolvida na capoeira (DAMATTA, 1997).

168 Número temático: Literatura, cultura e memória negra. A Cor das Letras - UEFS, n. 12, 2011 
basta jogar as pernas para o ar, me falaram os mestres. E acrescentaram: tem que saber o que se faz e agir no momento certo.

\section{REFERÊNCIAS}

ABIB, Pedro Rodolfo Jungers. Capoeira Angola: cultura popular e o jogo dos saberes na roda. Campinas/São Paulo: UNICAMP/CMU; Salvador: EDUFBA, 2005.

ABREU, Frederico José de. O barracão do Mestre Waldemar. Salvador: Org. Zarabatana, 2003.

COUTINHO, Daniel. O ABC da capoeira de Angola: os manuscritos de Mestre Noronha. Frederico Abreu. (Org.). Brasília: DEFER, Centro de Informação e Documentação sobre a Capoeira (CIDOCA/DF), 1993.

CSORDAS, Thomas. Corpo, significado, cura. Porto Alegre: UFRGS Ed., 2008.

DAMATTA, Roberto. Carnavais, malandros e heróis: para uma sociologia do dilema brasileiro. Rio de Janeiro: Rocco, 1997.

DESPRET, Vinciane. Ces émotions qui nous fabriquent; Ethnopsychologie des émotions. Paris: Les Empêcheurs de Penser en Rond/Le Seuil, 1999.

DIAS, Adriana Albert. Mandinga, manha \& malícia: uma história sobre os capoeiras na capital da Bahia (1910-1925). Salvador: EDUFBA, 2006.

DOWNEY, Greg. Learning Capoeira: Lessons in Cunning from an Afro-Brazilian Art. New York: Oxford University Press, 2005.

DOWNEY, Greg. Practice without Theory: a Neuroanthropological Perspectivee on Embodied Learning. Jornal of the Royal Anthropological Institute (N.S), 2010, p. 22-40.

GEERTZ, Clifford. A interpretação das Culturas. Rio de Janeiro: Zahar, 1989.

INGOLD, Timoty. Pare, olhe, escute - um prefácio. In: Idem. The Perceptionj of the Environment. Essays in Livelihood, Dwelling and Skill. Routledge: New York, 2000, p. 243-287. [Trad. Christine Zonzon].

LATOUR, Bruno. Como falar do corpo? A dimensão normativa dos estudos sobre a ciência. In: NUNES, J. A.; ROQUE, R. (Org.). Objetos impuros. Experiências em estudos sociais da ciência. Porto: Edições Afrontamento, 2007, p. 40-61

MERLEAU-PONTY, Maurice. Phénomènologie de la perception. Paris: Gallimard, 1945.

MERLEAU-PONTY, Maurice. Le visible et l'invisible. Paris: Gallimard, 1964

RABELO, Miriam; ALVES, Paulo C. Corpo: experiência e cultura. In: LEIBING, Ema. (Org.). Tecnologias do corpo: uma antropologia das medicinas no Brasil. Rio de Janeiro: Nau Editora, 2003.

REIS, Letícia Vidor de Souza. O mundo de pernas para o ar: a capoeira no Brasil. São Paulo: Publisher Brasil, 2000.

ZONZON, Christine Nicole. A roda de capoeira Angola: os sentidos em jogo, 2007. (Dissertação de Mestrado em Ciências Sociais). Universidade Federal da Bahia, UFBA, Salvador. 
ZONZON, Christine Nicole. Capoeira Angola, construção de identidades: uma investigação sobre as identidades construídas por grupos de capoeira angola em Salvador, 2001. (Dissertação de Maîtrise em Línguas e Civilização). Université Stendhal, UFR de Langues, Littératures et Civilisations Etrangères, Grenoble, França. 